\title{
NeuroImage
}

ELSEVIER

www.elsevier.com/locate/ynimg

NeuroImage 32 (2006) $1142-1149$

\section{A responsive MRI contrast agent to monitor functional cell status}

\author{
U. Himmelreich, ${ }^{\mathrm{a}, *}$ S. Aime, ${ }^{\mathrm{b}}$ T. Hieronymus, ${ }^{\mathrm{c}}$ C. Justicia, ${ }^{\mathrm{a}}$ F. Uggeri, ${ }^{\mathrm{d}}$ \\ M. Zenke, ${ }^{\mathrm{c}}$ and M. Hoehn ${ }^{\mathrm{a}}$ \\ ${ }^{a}$ In-vivo-NMR-laboratory, Max-Planck-Institute for Neurological Research with Klaus-Joachim-Zülch-Laboratories of the Max-Planck-Society \\ and the Faculty of Medicine of the University of Cologne, Gleueler Str. 50, Cologne D-50931, Germany \\ ${ }^{\mathrm{b}}$ Department of Chemistry, University of Torino, Italy \\ ${ }^{\mathrm{c}}$ Department of Cell Biology, Institute for Biomedical Engineering, Medical School and Helmholtz Institute for Biomedical Engineering, \\ Rheinisch-Westfälische Technische Hochschule, Aachen, Germany \\ ${ }^{\mathrm{d}}$ Bracco Imaging Spa, Milan, Italy
}

Received 14 March 2006; revised 25 April 2006; accepted 8 May 2006

Available online 11 July 2006

\begin{abstract}
It has been shown that insoluble Gd chelates are suitable MRI contrast agents for conditional activation by intracellular lipases. The DTPA-based, insoluble, inactive contrast agent was internalized into dendritic cells by phagocytosis. Cleavage of long aliphatic side chains by intracellular lipase activity leads to the contrast agents solubility and hereby its activation depending on the enzyme expression. Uptake and activation of the contrast agent was much reduced in Flt3 $+\mathrm{CD} 11 \mathrm{~b}+$ progenitor cells. Detectability limits in the $T_{1}$-weighted MR images were estimated in phantoms and in vivo in the rat brain. Marginal toxic effects were only observed at very high concentrations of the contrast agent. The chelate can easily be modified to be targeted by enzymes expressed during specific change of cell status like activation or differentiation. Such a system is suitable for functional cellular in vivo $M R$ imaging.

(c) 2006 Elsevier Inc. All rights reserved.
\end{abstract}

Keywords: Stem cells; Dendritic cells; Molecular imaging; Responsive contrast agents; Magnetic resonance imaging; Conditional activation

\section{Introduction}

Stable labeling of cells with either ultra-small paramagnetic iron oxide particles (USPIO) or lanthanide chelates has proven successful for MRI-based detection of cell deposits and their migration (Bulte et al., 2001; Crich et al., 2004; Hoehn et al., 2002; Modo et al., 2002). However, MRI only provides information about the location but not about the cellular functional status. This functional information could potentially be provided by lanthanide-based contrast agents that do

Abbreviations: CD11b, alpha M integrin; DOTA, dodecane-1,4,7,10tetraacetic acid; DTPA, diethylenetriamine pentaacetic acid; Flt3, fms-like tyrosine kinase 3; MRI, magnetic resonance imaging; $R_{1}$, relaxivity; $r_{1}$, relaxation rate $\left(1 / T_{1}\right)$; USPIO, ultra small paramagnetic iron oxide particles.

* Corresponding author. Fax: +49 2214726337.

E-mail address: himmelreich@nf.mpg.de (U. Himmelreich).

Available online on ScienceDirect (www.sciencedirect.com). not generate a contrast in an inactive state but can be activated by enzyme activity (Moats et al., 1997). Although less sensitive than USPIOs, lanthanide-based contrast agents have been used successfully for labeling stem cells and their monitoring in vivo (Crich et al., 2004; Modo et al., 2002; Modo et al., 2004). Hereby, the main advantage was seen in generating a hyperintense contrast in $T_{1}$-weighted MR images. The concept of inactive lanthanide-based contrast agents that can be activated by the action of enzymes has been introduced several years ago. Meade and co-workers developed probes that are responsive to $\beta$-galactosidase, which resulted in an increase of the $r_{1}$ relaxivity by $20 \%$ up to three times the $r_{1}$ of the "inactive" state (Louie et al., 2000; Moats et al., 1997). Although suitable for in vivo applications (Louie et al., 2000), the remaining relaxivity in the inactive state due to the secondary coordination sphere makes the probe too insensitive for in vivo cell tracking. We have chosen an approach suggested by Aime et al. where insoluble (and therefore inactive) Gd chelates are activated by enzymatic cleavage of long aliphatic side chains (Aime et al., 2002). Hereby, the insoluble chelate becomes soluble and generates an increase in $r_{1}$.

The aim of this study was to develop and test an insoluble Gdchelate-based contrast agent for conditional activation by intracellular lipase activity in dendritic cells and the progenitor cells as a proof-of-concept. Dendritic cells are antigen presenting cells of the system (Banchereau et al., 2000; Banchereau and Steinman, 1998). They develop from hematopoietic stem/progenitor cells through consecutive steps of differentiation that can be distinguished by phenotype, localization and function. Dendritic cells are specialized for uptake, processing and presentation of antigens and thus play a determining role for induction of primary immune responses and maintenance of tolerance (Banchereau et al., 2000). Throughout these successive processes of differentiation, maturation and activation dendritic cells express status-specific factors such as surface molecules, transcription factors, cytokines and enzymes (Banchereau et al., 2000; Banchereau and Steinman, 1998; Hacker et al., 2003; Hieronymus et al., 2005; Zenke and Hieronymus, 2006). 
In vivo images of cells implanted into the rat brain were acquired to validate the detectability limits for non-invasive MRI studies.

\section{Materials and methods}

\section{Contrast agent}

The Gd-DTPA chelate was linked with two long fatty acid chains $\left(\mathrm{COOC}_{17} \mathrm{H}_{35}\right)$ through ester bonds (Gd-DTPA-FA complex, see Fig. 1). The synthesis of the ligand was performed by reacting DTPA-bis-anhydride (Sigma-Aldrich, St. Louis, MO, USA) with the octadecanoic acid 2-(2-aminoethoxy)ethyl ester hydrochloride (stoichiometric ratio $1: 2$ ) in DMF at $60^{\circ} \mathrm{C}$. The aliphatic chain has been synthesized by dropwise addition of stearoyl chloride (SigmaAldrich, St. Louis, MO, USA) to a solution of 2-(2-aminoethoxy)ethanol hydrochloride (Sigma-Aldrich, St. Louis, MO, USA) at room temperature. The Gd(III) complex of the DTPAFA ligand has been obtained by adding a stoichiometric amount of $\mathrm{Gd}$ acetate to the solution of the ligand in methanol at $40^{\circ} \mathrm{C}$. After $1 \mathrm{~h}$, the clear solution was evaporated and dried. The analytical data (MS; IR and elemental analysis) were consistent with the proposed structure (Anelli et al., 2000).

Homogenized emulsions of the insoluble Gd-DTPA-FA particles were prepared by micronization by means of a high-pressure homogenizer (Mod. Panda NIRO-SOAVI). In addition, the particles were sonicated for $30 \mathrm{~min}$ in the respective medium immediately before cell experiments.

The size of the Gd-DTPA-FA particles after micronization and sonication was determined by light microscopy (Axiovert 10, Carl Zeiss GmbH, Oberkochen, Germany). Activation of the Gd-DTPAFA complex was tested in phantoms by addition of lipase (EC 3.1.1.3, Sigma-Aldrich, St. Louis, MO, USA) to the suspension of the insoluble contrast agent.

\section{Cells}

Bone marrow suspensions for generation of Flt3+ CD11b+ (fms-like tyrosine kinase $3, \mathrm{CD} 11 \mathrm{~b}=$ alpha $\mathrm{M}$ integrin) progenitor cells and dendritic cells were prepared from wild-type C57BL/6 and eGFP transgenic mice (Tg(ACTb-EGFP)1Osb (Okabe et al., 1997). Cells were cultured as previously described (Hieronymus et al., 2005). In brief, bone marrow suspensions were prepared from femur and tibia of hind legs and cells were seeded at $2 \times 10^{6}$ cells/ $\mathrm{ml}$ in RPMI 1640 medium supplemented with $10 \%$ FCS, 2 mM Lglutamine, $100 \mathrm{U} / \mathrm{ml}$ penicillin/streptomycin (all from Gibco-BRL, Grand Island, NY, USA) and $50 \mu \mathrm{M} \beta$-mercaptoethanol (SigmaAldrich, St. Louis, MO, USA) containing recombinant murine SCF (100 ng/ml), 25 ng/ml Flt3 ligand (FL; PeproTech, London, UK), $40 \mathrm{ng} / \mathrm{ml}$ recombinant long range IGF-1 (IGF-1; Sigma-Aldrich), 5 $\mathrm{ng} / \mathrm{ml}$ recombinant IL-6/soluble IL-6 receptor fusion protein (hyper-IL-6; Fischer et al., 1997), $20 \mathrm{U} / \mathrm{ml}$ of recombinant mouse GM-CSF and $10^{-6} \mathrm{M}$ dexamethasone. After 3 days in culture cells were subjected to Ficoll density gradient centrifugation (density $1.077 \mathrm{~g} / \mathrm{ml}$, PAA, Cölbe, Germany) to remove residual erythrocytes, dead cells and debris. Medium with growth factors was replenished every 2 days and cells were maintained at $2 \times 10^{-6}$ cells/ml density. After 7 days, differentiation into dendritic cells was induced and fully differentiated dendritic cells were obtained after 9 to 12 days in culture medium supplemented with $200 \mathrm{U} / \mathrm{ml}$ of recombinant mouse GM-CSF. Every 2 days medium was replenished and cells were maintained at $2 \times 10^{6}$ cells $/ \mathrm{ml}$ density. Cell numbers were determined with an electronic cell counter device (CASY1, Schärfe Systems, Reutlingen, Germany).

\section{Expression profiling}

RNA isolation, cDNA and cRNA synthesis, DNA microarray hybridization and analysis were performed as described before (Hieronymus et al., 2005). In brief, total RNA from Flt3+ CD11b+

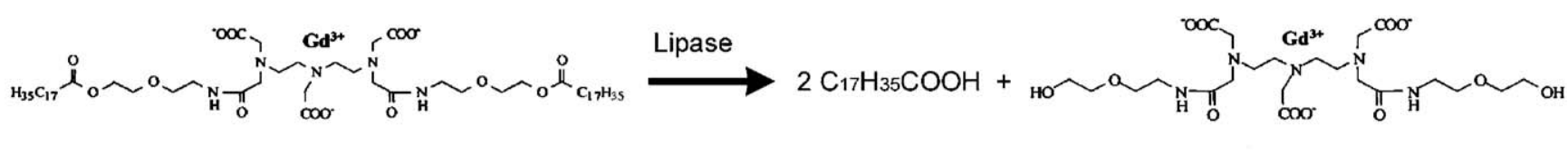

insoluble

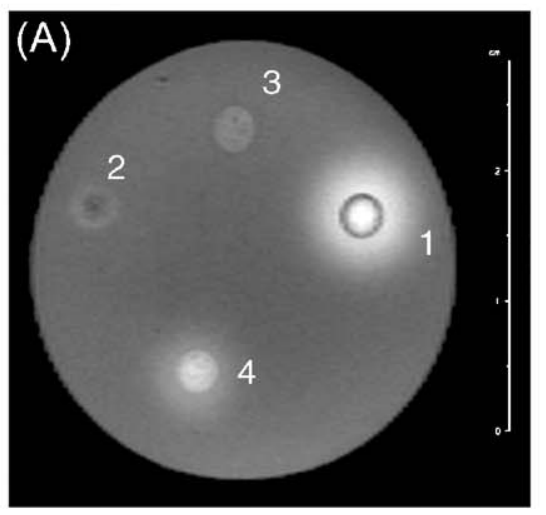

soluble

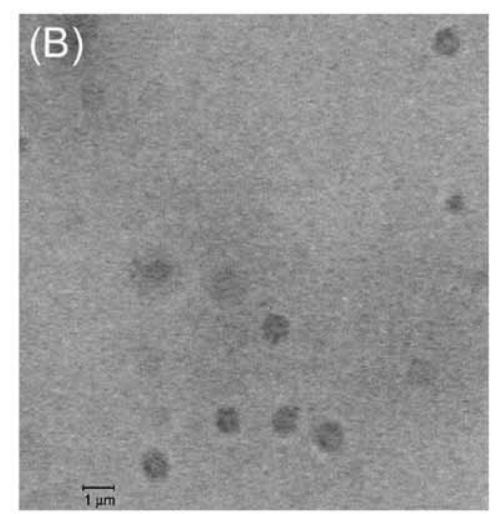

Fig. 1. Structure and enzymatic activation of the insoluble Gd-DTPA-FA complex. (A) The activation of the contrast agent is demonstrated in a $T_{1}$-weighted $3 \mathrm{D}$ MR image of a phantom containing solutions/suspensions of (1) $2 \mathrm{mM} \mathrm{Gd-DTPA}$ as a positive control, (2) the insoluble Gd-DTPA-FA complex (2 mM), (3) a suspension of lipase (EC 3.1.1.3) and (4) 2 mM Gd-DTPA-FA complex with $700 \mathrm{U}$ of lipase (EC 3.1.1.3). (B) Microscopy of the micronized Gd-DTPA-FAparticles indicates a homogeneous particle size between 0.5 and $1 \mu \mathrm{m}$. 
progenitor cells before and from dendritic cells 10 days after initiation of differentiation was isolated with RNeasy kits including DNAse digestion (Qiagen, Hilden, Germany). Five micrograms of total RNA was used to generate cRNA according to the Expression Analysis Technical Manual (Affymetrix, Santa Clara, CA, USA). Finally, $10 \mu \mathrm{g}$ cRNA per sample was hybridized to Affymetrix mouse MG-U74A or M 4302.0 arrays at $45^{\circ} \mathrm{C}$ for $16 \mathrm{~h}$. DNA chips were stained, washed and scanned according to the manufacturer's protocol and analyzed with the Affymetrix Microarray analysis software GCOS. Microarray data are available in GEO database (http://www.ncbi.nlm.nih.gov/geo/; series accession number GSE 575).

\section{Labeling}

For labeling with the Gd-DTPA-FA complex, cells of $60-70 \%$ confluence were washed and further incubated in $3.5-\mathrm{cm}$ culture dishes. The inactive contrast agent, suspended in the culture medium (final concentration 0.05 to $100 \mathrm{mM}$ ), was added to the respective culture medium, and incubation was continued for an additional period of 3 to $24 \mathrm{~h}$. At the end of the uptake experiments, the cells were washed with PBS (four times) and either used for further incubation without contrast agent, for in vitro testing in agar phantoms or for implantation in the rat brain. Incubation was carried out before or 6 to 10 days after initiation of differentiation into dendritic cells. Intracellular relaxation rates $\left(R_{1}\right)$ of Gd-DTPA-FA-labeled cell suspensions were expressed relative to $R_{1}$ of unlabeled cells $\left(R_{1}=R_{1}\right.$ (labeled cells) $-R_{1}$ (unlabeled cells)).

\section{Toxicity}

In order to investigate putative toxic effects by labeling of the cells with high concentrations of the contrast agent, Trypan Blue exclusion was used to measure cell viability. Long-time effects were studied by continued incubation of labeled cells in culture medium without Gd chelates and comparison of cell viability with unlabeled control cells after $48 \mathrm{~h}$.

\section{Phantoms}

Phantoms were made using culture dishes $(3.5-\mathrm{cm}$ diameter) filled with $1.6 \%$ agar (Sigma-Aldrich). Drill holes (3-mm diameter) were filled with $10^{2}$ to $10^{6}$ cells suspended in $10 \mu$ agar (1.6\%). After solidification, drill holes were closed with additional agar. For supernatants, phantoms consisting of $3-\mathrm{mm}$ capillaries were used.

\section{Gd concentration}

Intracellular Gd-DTPA concentrations were determined after lyophilization of labeled cells. Hereby, washed cells suspended in $200 \mu 1$ saline were snap frozen in liquid nitrogen and mechanically destroyed by grinding and subsequent sonication. The $T_{1}$ values of the supernatant were determined after centrifugation. The GdDTPA concentration was determined by comparison of the $R_{1}$ relaxation rate with those of standard curves obtained using GdDTPA solutions ( 0.01 to $100 \mathrm{mM}) . T_{1}$ values were determined at 7 $\mathrm{T}$ and $25^{\circ} \mathrm{C}$ using inversion recovery experiments.

All concentrations are expressed in mol per number of cells. Cell numbers were determined immediately before experiments.
MRI

All MR images were acquired using a Bruker Biospin 7.0 T scanner (Ettlingen, Germany; horizontal bore, $30 \mathrm{~cm}$ ) equipped with actively shielded gradients $\left(200 \mathrm{mT} \mathrm{m}^{-1}\right.$ for animal experiments and $400 \mathrm{mT} \mathrm{m}^{-1}$ for phantoms). Purpose-built radiofrequency coils were used for phantoms (transmit-receive coil 4.5$\mathrm{cm}$ diameter) and animal experiments (12-cm Helmholtz coils for excitation and a 3-cm surface coil for detection).

2D multi-slice-multi-echo (MSME) experiments were acquired for the calculation of $T_{2}$-maps and inversion recovery experiments (IR SNAP) for $T_{1}$-maps $\left(256^{2}\right.$ matrix, FOV: $3.7 \times 3.7 \mathrm{~cm}, 0.8-\mathrm{mm}$ slice thickness). The MSME experiments for the calculation of $T_{2^{-}}$ maps were acquired with $\mathrm{TR}=10,000 \mathrm{~ms}$ and $16 \mathrm{TE}$ increments of $8.5 \mathrm{~ms}$. The $T_{1}$-maps were acquired with inversion delays ranging from 18 to $5000 \mathrm{~ms}$. $T_{1}$-maps were utilized for the calculation of $R_{1}$ relaxation rates. 3D $T_{1}$ - and $T_{2}{ }^{*}$-weighted MR images were acquired with high-resolution using gradient echo sequences (FLASH, TR $=80 \mathrm{~ms}, \mathrm{TE}=5 \mathrm{~ms}$, flip angle $65^{\circ}$ for $T_{1}$ weighting and $\mathrm{TR}=160 \mathrm{~ms}, \mathrm{TE}=20 \mathrm{~ms}$, flip angle $30^{\circ}$ for $T_{2} *$ weighting), respectively. The field-of-view was $3 \times 3 \times 1 \mathrm{~cm}$ for animal experiments and $3.7 \times 3.7 \times 1 \mathrm{~cm}$ for phantoms, respectively. The isotropic spatial resolution was between 78 and $110 \mu \mathrm{m}$. Images were processed using Paravision 3.0.2 (Bruker Biospin), NIH ImageJ and in-house developed algorithms for the calculation of $T_{1}$ - and $T_{2}$-maps.

$T_{1}$ values of stock solutions of Gd-DTPA, the inactive and the activated Gd-DTPA-FA were determined at $0.47,4.7$ and $7 \mathrm{~T}$ at $25^{\circ} \mathrm{C}$ using inversion recovery experiments. The concentration range to calculate the respective relaxivities $r_{1}$ was 0.01 to $100 \mathrm{mM}$.

\section{Animals}

All experiments were performed in accordance with the National Institutes of Health animal protection guidelines and were approved by the local governmental authorities. Two to four depots of $10^{4}$ to $10^{6}$ cells suspended each in $2 \mu \mathrm{l}$ were stereotactically implanted into the border between the cortex and the corpus callosum $(0.5 \mathrm{~mm}$ anterior (two depots) or $0.7 \mathrm{~mm}$ anterior/ 0.3 posterior (four depots), $3.0 \mathrm{~mm}$ lateral to bregma, 2.0 $\mathrm{mm}$ ventral from the dural surface) in normal Wistar rats $(n=4$, $300-550 \mathrm{~g}$ ) in the right and left hemisphere according to (Hoehn et al., 2002). Homogeneous cell suspensions in PBS were delivered to the implantation site through a Hamilton syringe (outer needle diameter, $0.4 \mathrm{~mm}$ ) and a micropump system. Animals were imaged immediately after implantation and 4-21 days thereafter using $1 \%$ halothane anesthesia in $\mathrm{O}_{2}: \mathrm{N}_{2} \mathrm{O}(35: 65 \%)$. MRI experiments were conducted at 7.0 T using 3D spin- and gradient-echo sequences similar to the phantom experiments. The spatial resolution was $78 \times 78 \times 110 \mu \mathrm{m}^{3}$.

\section{Results}

\section{Characterization of the contrast agent}

The diameter of the Gd-DTPA-FA particles after micronization and sonication varied between 0.5 and $1 \mu \mathrm{m}$ (Fig. 1). The $R_{1}$ relaxation rate of the inactive Gd-DTPA-FA complex suspended in saline $(0.9 \% \mathrm{NaCl})$ was $0 \mathrm{mM}^{-1} \mathrm{~s}^{-1}$ at $0.47,4.7$ and $7.0 \mathrm{~T}$ and 298 $\mathrm{K}$. Addition of an esterase (EC 3.1.1.3) to a suspension of the Gd- 


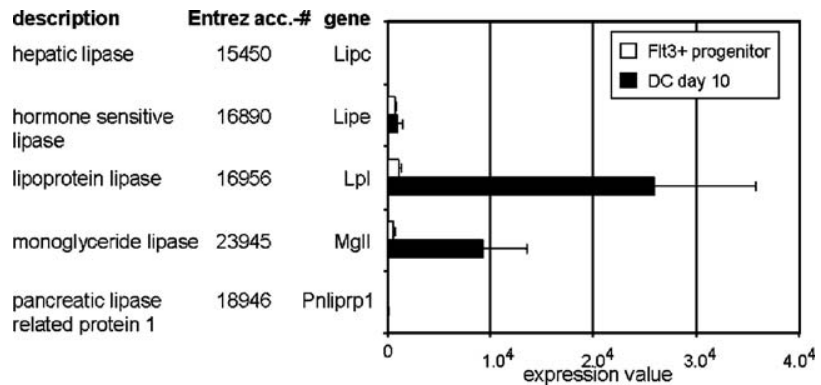

Fig. 2. Lipase gene expression in Flt3 $+\mathrm{CD} 11 \mathrm{~b}+$ progenitor cells and dendritic cells analyzed by DNA microarrays. Results shown are mean intensity values \pm SD of normalized data from six independent experiments for Flt3+ CD11b+ progenitor cells before and for dendritic cells 10 days after initiation of differentiation. Representative microarray data are available in GEO database (series accession number GSE 575).

DTPA-FA complex resulted in immediate enzymatic activation of the contrast agent due to cleavage of the fatty acid residues, as illustrated in Fig. 1. The relaxivity $r_{1}$ of the activated chelate in saline was $4.7 \pm 0.1 \mathrm{mM}^{-1} \mathrm{~s}^{-1}$ at $0.47 \mathrm{~T}(n=3), 4.1 \pm 0.1 \mathrm{mM}^{-1}$ $\mathrm{s}^{-1}$ at $4.7 \mathrm{~T}(n=3)$ and $3.9 \pm 0.1 \mathrm{mM}^{-1} \mathrm{~s}^{-1}$ at $7.0 \mathrm{~T}(n=3)$, which is in agreement with the relaxivity of Gd-DTPA under similar conditions (Donahue et al., 1994; Koenig and Brown, 1987; Stanisz and Henkelman, 2000).

\section{Lipase expression}

Uptake of foreign particles is a hallmark of dendritic cells and labeling with contrast agents for MRI-based detection was previously described (Ahrens et al., 2003; de Vries et al., 2005). To test whether dendritic cells are suitable for enzymatic activation of insoluble Gd chelates linked with long aliphatic chains by ester bond, expression of lipases was analyzed in in vitro differentiated dendritic cells and in the undifferentiated Flt3+ CD11b+ progenitor cells. RNA from six independent experiments with Flt3+ $\mathrm{CD} 11 \mathrm{~b}+$ progenitors and dendritic cells was prepared and subjected to transcriptional profiling employing Affymetrix GeneChip arrays. According to definitions provided by the NetAffx Analysis Center (http://www.affymetrix.com/analysis/ index.affx) five lipases and lipase-related factors were characterized (Fig. 2). Pancreatic lipase-related protein 1 (Pnliprp1) and hepatic lipase (Lipc), which represents an archetypical EC 3.1.1.3 enzyme, were not found to be expressed. However, gene expression of hormone sensitive lipase (HSL/Lipe), lipoprotein lipase (Lpl; EC 3.1.1.34) and monoclyceride lipase (Mgll; EC 3.1.1.23) was found in Flt3+ CD11b+ progenitor cells and dendritic cells. Furthermore, expression levels of Lpl and Mgll were highly increased in fully differentiated dendritic cells compared to the precursor cells. Thus, dendritic cells emerge to be particularly well suited for conditional activation of insoluble Gd-DTPA-FA complexes by intracellular lipase activity.

\section{In vitro characterization}

The phagocytic uptake of the Gd-DTPA-FA complex was tested by incubation with Flt3 $+\mathrm{CD} 11 \mathrm{~b}+$ progenitor cells and fully differentiated dendritic cells for 2 to 24 h. Fig. 3 shows that internalization and activation by dendritic cells was significantly higher than for the progenitor cells. Uptake of the particles was tested after lyophilization, determination of the $R_{1}$ relaxation rate of the supernatant and comparison with Gd-DTPA stock solution of a concentration range between 0.05 and $100 \mathrm{mM}$. The uptake was almost linear with increasing concentrations for dendritic cells and saturated for progenitor cells after a 24-h incubation period (Fig. 3). In contrast to the linear uptake, the $R_{1}$ relaxation rate was saturated for Gd-DTPA-FA concentrations $>15 \mathrm{mM}$ in the cell culture medium of dendritic cells. As shown in the insert of Fig. 3, a non-linear relationship between $R_{1}$ and [Gd-DTPA-FA] in the cell culture medium was evident for concentrations as low as $5 \mathrm{mM}$. The $T_{1}$ relaxation time of unlabeled cells ( 4.5 to $5.0 \mathrm{~s}$ ) was used as a reference point in all phantom experiments.

Fig. 4 shows the $R_{1}$ relaxation rate of dendritic cells for three different contrast agent concentrations immediately after a

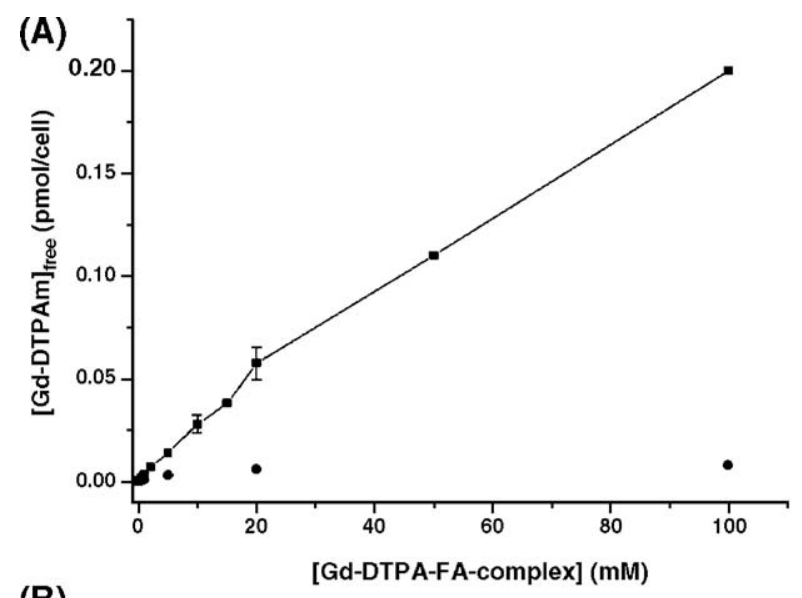

(B)

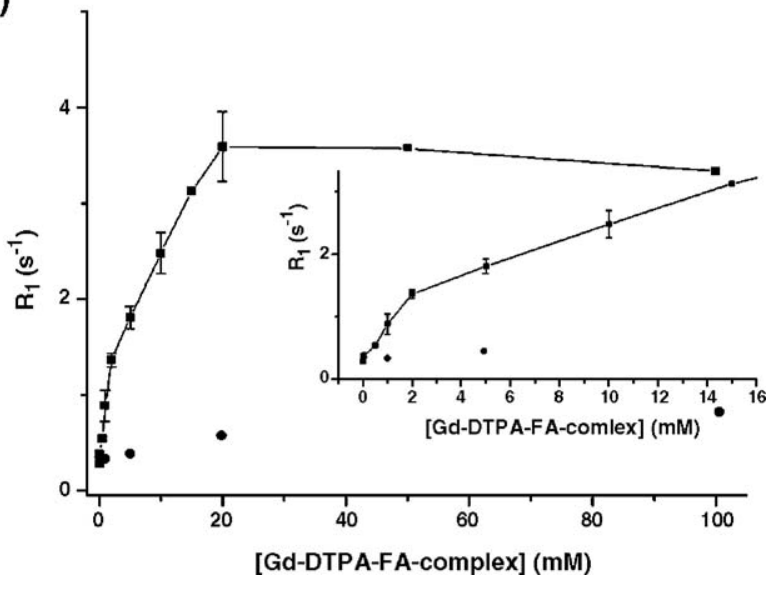

Fig. 3. (A) Internalization of Gd-DTPA-FA into dendritic cells (squares) and Flt3 + CD11b+ progenitor cells (circles) after 24-h incubation with the respective concentration of the contrast agent in the cell culture medium. Intracellular Gd-DTPA concentration was determined for 1 to $2 \times 10^{6}$ cells after lysis and comparison of $R_{1}$ of the supernatant with a calibration curve ( $R_{1}$ of Gd-DTPA solutions in concentration range 0.01 to $100 \mathrm{mM}$ ). $R_{1}$ values were calculated from inversion recovery experiments (IR-SNAP) using inversion delays ranging from 18 to $5000 \mathrm{~ms}$. (B) Relaxation rate $R_{1}$ of intracellularly activated Gd-DTPA-FA particles relative to $R_{1}$ of unlabeled cells $\left(R_{1}=R_{1}\right.$ (labeled cells) $-R_{1}$ (unlabeled cells)) as a function of the amount of Gd-DTPA-FA in the culture medium. The squares show the $R_{1}$ relaxation rates of dendritic cells and the circles $R_{1}$ of Flt3+ $\mathrm{CD} 11 \mathrm{~b}+$ progenitor cells. The insert is a magnification of the low concentration range. The $R_{1}$ was determined using agar phantoms containing 50,000 cells $\mu \mathrm{l}^{-1}$. $R_{1}$ values were calculated from inversion recovery experiments (IR-SNAP) using inversion delays ranging from 18 to $5000 \mathrm{~ms}$. Results are shown as mean values \pm SD. 

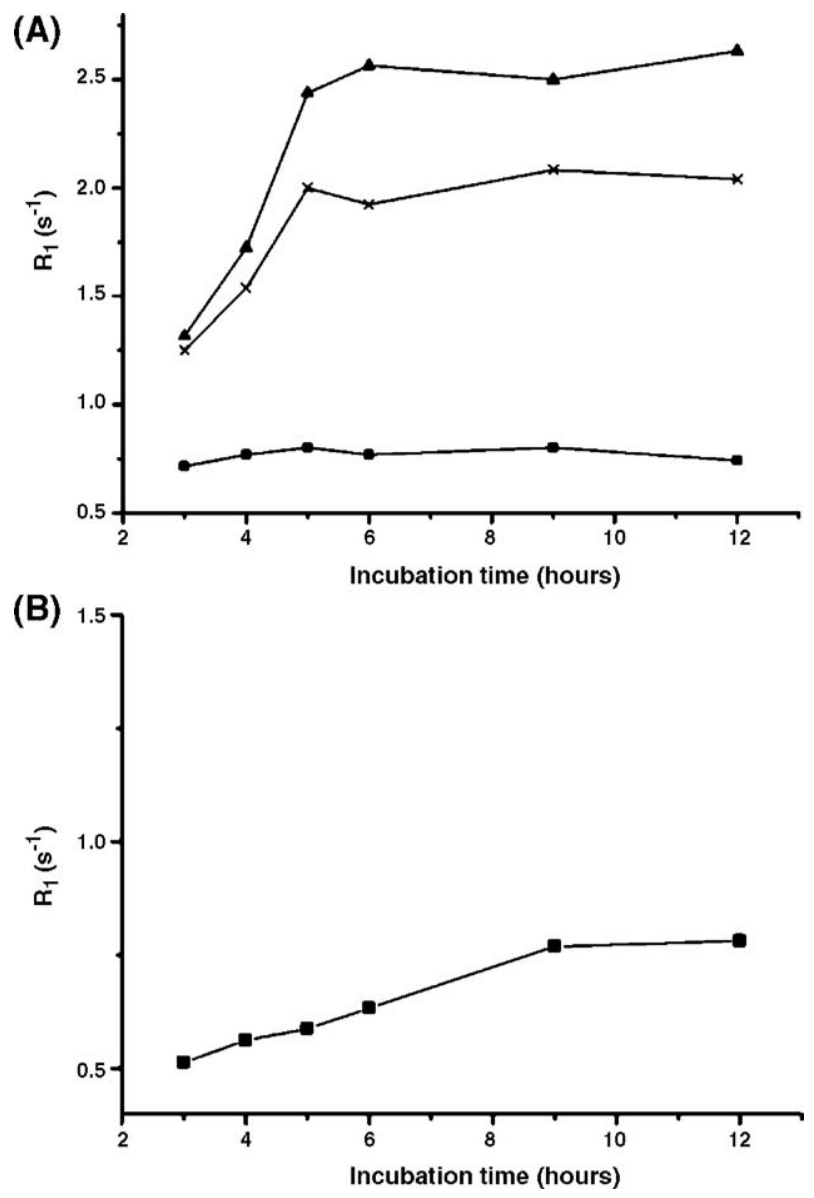

Fig. 4. Formation of soluble Gd-DTPA complexes in dendritic cells and in Flt3 $+\mathrm{CD} 11 \mathrm{~b}+$ progenitor cells. Cells were incubated for $3 \mathrm{~h}$ with the $\mathrm{Gd}-$ DTPA-FA particles present in the culture medium. Thereafter, cells were washed with PBS and continuously incubated in culture medium free of the contrast agent. (A) The $R_{1}$ relaxation rates were determined for dendritic cells immediately after the incubation with the contrast agent and 1, 2, 3, 6 and $9 \mathrm{~h}$ thereafter using a phantom containing 50,000 cells $\mu \mathrm{l}^{-1} \cdot R_{1}$ values were calculated from inversion recovery experiments (IR-SNAP) using inversion delays ranging from 18 to $5000 \mathrm{~ms}$. The initial concentration of the Gd-DTPA-FA particles was $1 \mathrm{mM}$ (squares), $5 \mathrm{mM}$ (crosses) and 15 $\mathrm{mM}$ (triangles). (B) Formation of soluble Gd-DTPA complexes in Flt3+ $\mathrm{CD} 11 \mathrm{~b}+$ progenitor cells after the 3 -h incubation period with medium containing 100 Gd-DTPA-FA. Cells were washed and transferred to contrast agent free medium after the initial incubation period and $R_{1}$ relaxation rates were determined as for dendritic cells.

3-h incubation period and after further incubation in Gd-DTPA-FAfree culture medium. Activation of the chelate occurred immediately with the uptake for the lowest concentration (1 $\mathrm{mM})$. Activation after continued incubation reached its maximum within an additional incubation period of three hours for even the highest concentration $(15 \mathrm{mM})$. Interestingly, the $R_{1}$ relaxation rate of the cell suspensions, after incubation for $3 \mathrm{~h}$ with and an additional time without Gd-DTPA-FA, was only marginally lower than after incubation for $24 \mathrm{~h}$ in the presence of Gd-DTPA-FA, indicating that the maximal intracellular Gd-DTPA-FA concentration is reached after only a few hours of incubation. This was also confirmed by experiments, in which cells were incubated in GdDTPA-FA-containing medium and harvested after 3, 6, 9, 12 and $24 \mathrm{~h}$. The maximum $R_{1}$ relaxation rate was always reached within
$9 \mathrm{~h}$ of incubation in the presence of Gd-DTPA-FA. Fig. 3 indicates that the maximum intracellular concentration for Flt3+ $\mathrm{CD} 11 \mathrm{~b}+$ progenitor cells was comparable to that in dendritic cells incubated in culture medium containing $1 \mathrm{mM}$ Gd-DTPA-FA. In contrast to dendritic cells, complete activation occurred not immediately but with a time delay in the progenitor cells (Fig. 4B). This is an indirect confirmation of the lower lipase activity in these cells (Fig. 2).

Fig. 5 shows a $T_{1}$-weighted image of a $3 \mathrm{D}$ data set and corresponding signal intensities of a phantom containing various amounts of dendritic cells that have been incubated in the presence of $0.05 \mathrm{mM}$ to $20 \mathrm{mM}$ Gd-DTPA-FA. Under those imaging conditions, approximately $10^{3}$ cells $\mu 1^{-1}$ labeled in medium containing $10 \mathrm{mM}$ Gd-DTPA-FA is the lowest amount of cells reliably detectable in vitro. Labeling with higher concentrations does not increase signal intensity. Fig. 5 also indicates that the Gd-DTPAFA complex was activated intracellularly as the drill hole containing the supernatant of the cell suspension is not distinguishable from the background. This was confirmed by $T_{1}$ measurements of the supernatant of cells labeled for $24 \mathrm{~h}$ in the presence of 0.05 to 100 mM Gd-DTPA-FA. The $T_{1}$ values were not significantly different from the plain culture medium when Gd-DTPA-FA was added in a concentration range of 0.05 to $10 \mathrm{mM}$. Marginally increased $R_{1}$ in the supernatant containing Gd-DTPA-FA in concentrations $>10 \mathrm{mM}$ were noticed for some experiments. These increases corresponded to Gd-DTPA concentrations $<1 \mathrm{mM}$ in all experiments. The most likely cause for this 'extracellular' Gd-DTPA is cell lysis.

Toxicity

To detect potential toxic effects of the Gd-DTPA-FA complex in its inactive and activated form, the amount of dead cells was determined after 6,12 and $24 \mathrm{~h}$ of incubation in medium containing 1, 10, 20 and $100 \mathrm{mM}$ of the contrast agent. Fig. 6 indicates marginally increased cell death for concentrations higher than 10 $\mathrm{mM}$ after $24 \mathrm{~h}$ of incubation in the presence of Gd-DTPA-FA. Adverse effects on the cell viability of Gd-labeled cells were also detected after continued incubation $(48 \mathrm{~h})$ in culture medium free of the contrast agent, and by comparison with unlabeled, control cells if contrast agent concentrations were higher than $10 \mathrm{mM}$.

\section{In vivo characterization}

In order to validate cell detectability in an animal model, dendritic cells (suspended in $2 \mu \mathrm{l}$ ) were implanted in rat brains immediately after labeling with Gd-DTPA-FA. The minimum number of cells detectable by MRI was approximately $20,000 \mu \mathrm{l}^{-1}$ for up to $72 \mathrm{~h}$ after implantation. 50,000 cells $\mu \mathrm{l}^{-1}$ were detectable for up to eight days after implantation (see Fig. 5). Similar to the in vitro experiments, labeling of cells with concentrations of GdDTPA-FA higher than $15 \mathrm{mM}$ did not further improve visualization of the cells in the animal brain.

\section{Discussion}

We have demonstrated the intracellular activation of an insoluble $\mathrm{Gd}$ chelate by enzymatic hydrolysis in dendritic cells. To our knowledge, this is the first report on the conditional activation of contrast agents by enzymes intrinsic to the cells. Labeling was efficient for the visualization of dendritic cells in 

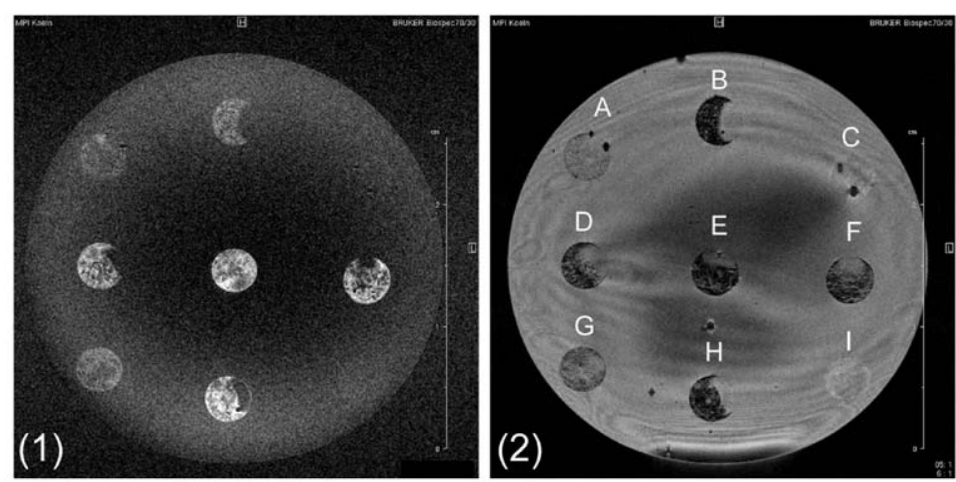

(3)

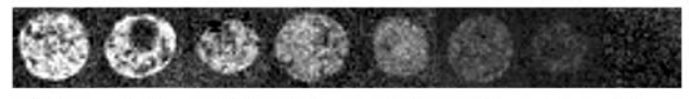

SI: $100087 \quad 72 \quad 69 \quad 57 \quad 43 \quad 23 \quad 12$

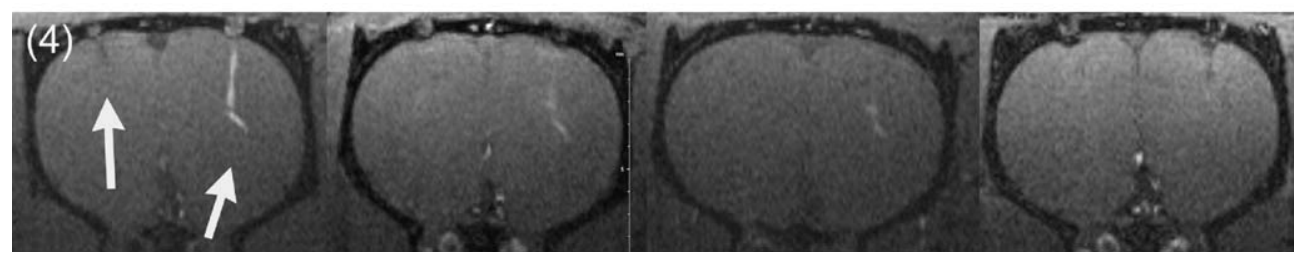

Fig. 5. Agar phantoms containing dendritic cells labeled with the Gd-DTPA-FA complex. 3D $T_{1}$-weighted ((1), TR $=80 \mathrm{ms,} \mathrm{TE}=5 \mathrm{~ms}$, flip angle $\left.65^{\circ}\right)$ and $T_{2}{ }^{*}$-weighted ( (2), TR $=160 \mathrm{~ms}, \mathrm{TE}=20 \mathrm{~ms}$, flip angle $\left.30^{\circ}\right)$ gradient echo MR images with an isotropic resolution of $80 \mu \mathrm{m}$. Cells were incubated for $24 \mathrm{~h}$ in culture medium containing suspended Gd-DTPA-FA particles. The drill holes were filled with $10 \mu \mathrm{l}$ suspensions containing (A) $510^{4}$ cells incubated in $2 \mathrm{mM}$ Gd-DTPA-FA, (B) $210^{5}$ cells incubated in 0.5 Gd-DTPA-FA, (C) cell culture medium of (E), (D) $510^{4}$ cells incubated in $10 \mathrm{mM} \mathrm{Gd-DTPA-FA,} \mathrm{(E)} 210^{5}$ cells incubated in $10 \mathrm{mM}$ Gd-DTPA-FA, (F) $210^{5}$ cells incubated in $20 \mathrm{mM}$ Gd-DTPA-FA, (G) $510^{4}$ cells incubated in 5 mM Gd-DTPA-FA, (H) $210^{5}$ cells incubated in $50 \mathrm{mM}$ Gd-DTPA-FA, and (I) $210^{5}$ cells incubated without contrast agent (control). (3) To determine the minimum number of Gd-DTPA-FAlabeled cells detectable by MRI in a phantom, $T_{1}$-weighted 3D MR images of eight pellets containing different amounts of dendritic cells labeled in medium containing $10 \mathrm{mM}$ Gd-DTPA-FA were directly compared. The drill holes contained $210^{5}, 110^{5}, 510^{4}, 110^{4}, 510^{3}, 210^{3}, 110^{3}, 510^{2}$ cells $\mu 1^{-1}$ (left to right). The minimum detectable number of labeled cells was estimated at $10^{3}$ cells $\mu^{-1}$. (4) Cells were stereotactically grafted into the border between the cortex and the corpus callosum of the rat brain. The $T_{1}$-weighted MR images (FLASH, TR $=80 \mathrm{~ms}, \mathrm{TE}=5 \mathrm{~ms}$, flip angle $65^{\circ}$ ) were acquired $1 \mathrm{~h}, 4$ days, 10 and 21 days after implantation of $10^{5}$ cells suspended in $2 \mu$. Cells in the right hemisphere were incubated for $24 \mathrm{~h}$ in the presence of $10 \mathrm{mM}$ Gd-DTPA-FA. Unlabeled cells $\left(10^{5}\right.$ in $2 \mu$ l) were implanted in the left hemisphere (indicated by the left arrow in the left image). Cells were washed three times with PBS before implantation.

phantoms and in the brain of animals. Toxicity was a concern only for concentrations of the contrast agent in the cell culture medium of larger than $20 \mathrm{mM}$. This could be significantly minimized in the future by utilization of more stable, non-linear Gd chelates (for example DOTA-like molecules) as the toxic effect of the $\mathrm{Gd}$ chelate is most likely due to the release of free gadolinium. Due to the relatively low number of implanted cells relative to the cell number in the host and due to rapid dilution of possibly released free Gd, no adverse effect for the host is expected.

Previous studies on the visualization of cellular events were mainly based on the specific binding and accumulation of the contrast agent at the surface of the targeted cells (Aime et al., 2002). Studies on enzymatic activation of otherwise inactive contrast agent are sparse. A precondition for the $T_{1}$ inactivity of a lanthanide-based contrast agent in its native state is the suppression of the water exchange with the Gd atoms of the chelate. It was previously suggested to block water coordination to the inactive contrast agent by introduction of functional groups that coordinate to the $\mathrm{Gd}$ ion. Activation would occur by enzymatic cleavage of these functional groups after expression of a targeted enzyme (Louie et al., 2000; Moats et al., 1997). A disadvantage of such probes is the remaining activity in the inactive state due to the secondary coordination sphere of the water. In contrast, the insoluble Gd-DTPA-FA complex used in this study did not contribute to an increased $r_{1}$ relaxivity in its inactive state. This resulted in a higher sensitivity due to a larger proportional increase in the relaxivity between inactive and activated contrast agent.

Although labeling of dendritic cells by endocytotic up-take of iron-oxide particles and their visualization in $T_{2}{ }^{*}$-weighted images is more sensitive than visualization of lanthanide labeled cells in $T_{1}$-weighted images (Ahrens et al., 2003), this method does not provide information on the functional status of the cell. Several thousand cells can be visualized in $T_{1}$-weighted MR images after labeling with Gd-DTPA-FA particles. Gd-DTPA-FA labeling of dendritic cells was efficient for their visualization not only in phantoms but also in in vivo animal experiments. Although this is currently not efficient enough for monitoring the migration of small cell clusters, it is potentially useful for the visualization of accumulated cell clusters and their functional changes, for example, in the process of inflammation. Sensitivity can be improved by using more sensitive Gd-based contrast agents (Aime et al., 2002). A potential application of this concept of contrast agents is the visualization of changes to the cell status of dendritic cells. Depending on their developmental origin, cytokine activators, surface antigens and functional capacity, dendritic cells are essential for the initiation of the immune response, stimulation of $\mathrm{B}$ and $\mathrm{T}$ lymphocytes, the regulation of 

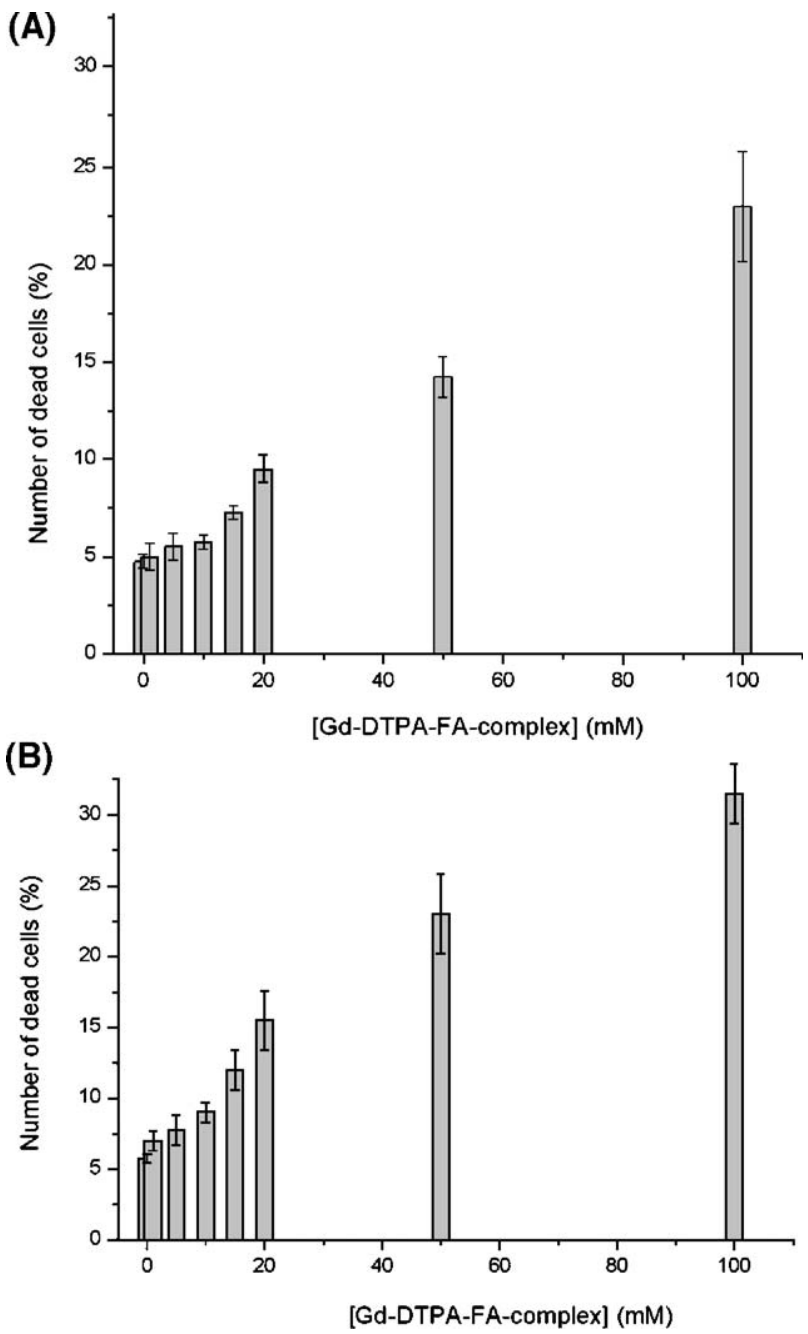

Fig. 6. The amount of dead cells was determined by Trypan Blue exclusion immediately after labeling (A) and $48 \mathrm{~h}$ after continued incubation in contrast agent free medium (B). Results are shown as mean values \pm SD.

the balance between induction of immunity and tolerance and others (Banchereau and Steinman, 1998). Hereby, dendritic cells go through processes of activation and maturation with the expression of specific enzymes (like oxidases, peptidases etc.) that can be visualized by the activation of a Gd-DTPA-FA complex if the link between the aliphatic side chain and the Gd chelate is modified to form a target of the respective enzyme. Such contrast agents would indicate onset and progress of inflammatory processes but could also be extended to other cell types and processes like cell differentiation. The once activated contrast agent remains activated. The delayed intracellular activation of the Gd-DTPA-FA complex in Flt3+ CD11b+ progenitor cells compared to dendritic cells indicated the potential of such responsive contrast agents to assess enzyme activity non-invasively.

Similar to previous observations, the relaxivity in the cell suspensions is "quenched" by high concentrations $(>15 \mathrm{mM})$ of internalized Gd chelates (Crich et al., 2004; Lewin et al., 2001). In contrast to the $\mathrm{Gd}$ chelate in free solution, a concentration dependence of the $r_{1}$ relaxivity has been observed after internalization into cells. Most likely explanations for this phenomenon are a decreased molecular mobility due to interactions with macromolecules for an unproportionally high relaxation rate at low concentrations of the contrast agent, resulting in an increase in $R_{1}$ (Stanisz and Henkelman, 2000); and the lack of exchanging water molecules in endosomes for unproportionally low relaxivities at high concentrations (Terreno et al., 2005, 2006). The relaxivity of $\mathrm{Gd}$ chelates entrapped in endosomes is reduced if the number of exchanging water protons is limited. In such a situation the water exchange across the endosome membrane influences $r_{1}$. Although of disadvantage for immediate cell detectability, "overloaded" cells would be detectable with a similar relaxivity even if the label is diluted due to cell proliferation.

The uptake of the insoluble Gd-DTPA-FA particles was satisfactory for dendritic cells. The concept of insoluble $\mathrm{Gd}$ chelates and their intracellular activation will be further extended to other cell types if the size of the insoluble particles can be further reduced. Promising approaches have been introduced in the field of drug development, which may be adopted for the internalization of contrast agents (Merisko-Liversidge et al., 2003).

In conclusion, we were able to show in a proof-of-concept study that insoluble Gd chelates are suitable contrast agents for conditional activation by intracellular lipases. The Gd chelate can easily be modified to form a target for other enzymes that are specifically expressed during changes of cell status (e.g., activation, differentiation etc.).

\section{Acknowledgments}

We gratefully acknowledge the financial support by the European Commission for an International Re-integration grant to UH (\#13080) and the European networks of excellent, EC-FP6project European Molecular Imaging Laboratory (EMIL), LSHCCT-2004-503569 and Diagnostic Molecular Imaging (DiMI), LSHB-CT-2005-512146. MZ and TH are supported by funds from the Interdisciplinary Center for Clinical Research "BIOMAT" within the Faculty of Medicine at the RWTH Aachen University (VV B110-d and VV B112-a), Deutsche Forschungsgemeinschaft (DFG, Ze432.1 and Ze432.2) and the Bundesministerium für Bildung und Forschung (BMBF, 0311592A and 01GN0543).

\section{References}

Ahrens, E.T., Feili-Hariri, M., Xu, H., Genove, G., Morel, P.A., 2003. Receptor-mediated endocytosis of iron-oxide particles provides efficient labeling of dendritic cells for in vivo MR imaging. Magn. Reson. Med. 49, 1006-1013.

Aime, S., Cabella, C., Colombatto, S., Crich, S.G., Gianolio, E., Maggioni, F., 2002. Insight into the use of paramagnetic Gd(III) complexes in MRmolecular imaging investigations. J. Magn. Reson. Imag. 16, 394-406.

Anelli, P., Lattuada, L., Uggeri, F., Lux, G., Serleti, M., Gabellini, M., Tournier, H., 2000. Amphipatic Polycarboxylic Chelates and Complexes with Paramagnetic Metals as MRI Contrast Agents. Patent WO 00/30688.

Banchereau, J., Steinman, R.M., 1998. Dendritic cells and the control of immunity. Nature 392, 245-252.

Banchereau, J., Briere, F., Caux, C., Davoust, J., Lebecque, S., Liu, Y.J., Pulendran, B., Palucka, K., 2000. Immunobiology of dendritic cells. Ann. Rev. Immunol. 18, 767-811.

Bulte, J.W.M., Douglas, T., Witwer, B., Zhang, S.C., Strable, E., Lewis, B.K., Zywicke, H., Miller, B., van Gelderen, P., Moskowitz, B.M., 
Duncan, I.D., Frank, J.A., 2001. Magnetodendrimers allow endosomal magnetic labeling and in vivo tracking of stem cells. Nat. Biotechnol. 19, $1141-1147$

Crich, S.G., Biancone, L., Cantaluppi, V., Duo, D., Esposito, G., Russo, S., Camussi, G., Aime, S., 2004. Improved route for visualization of stem cells labeled with a Gd-/Eu-chelate as a dual (MRI and fluorescence) agent. Magn. Reson. Med. 51, 938-944.

de Vries, I.J.M., Lesterhuis, W.J.L., Barentsz, J.O., Verdijk, P., van Krieken, J.H., Boerman, O.C., Oyen, W.J.G., Bonenkamp, J.J., Boezeman, J.B., Adema, G.J., Bulte, J.W.M., Scheenen, T.W.J., Punt, C.J.A., Heerschap, A., Figdor, C.G., 2005. Magnetic resonance tracking of dendritic cells in melanoma patients for monitoring of cellular therapy. Nat. Biotechnol. 23, 1407-1413.

Donahue, K.M., Burstein, D., Manning, W.J., Gray, M.L., 1994. Studies of Gd-DTPA relaxivity and proton exchange rates in tissue. Magn. Reson. Med. 32, 66-76.

Fischer, M., Goldschmitt, J., Peschel, C., Brakenhoff, J.P., Kallen, K.J., Wollmer, A., Grotzinger, J., Rose-John, S., 1997. A bioactive designer cytokine for human hematopoietic progenitor cell expansion. Nat. Biotechnol. 15, 142.

Hacker, C., Kirsch, R.D., Ju, X.S., Hieronymus, T., Gust, T.C., Kuhl, C., Jorgas, T., Kurz, S.M., Rose-John, S., Yokota, Y., Zenke, M., 2003. Transcriptional profiling identifies Id2 function in dendritic cell development. Nat. Immunol. 4, 380-386.

Hieronymus, T., Gust, T.C., Kirsch, R.D., Jorgas, T., Blendinger, G., Goncharenko, M., Supplitt, K., Rose-John, S., Muller, A.M., Zenke, M., 2005. Progressive and controlled development of mouse dendritic cells from Flt $(3+) \mathrm{CD} 11 \mathrm{~b}(+)$ progenitors in vitro. J. Immunol. 174, $2552-2562$.

Hoehn, M., Küstermann, E., Blunk, J., Wiedermann, D., Trapp, T., Wecker, S., Föcking, M., Arnold, H., Heschler, J., Fleischmann, B.K., Schwindt, C., Bührle, C., 2002. Monitoring of implanted stem cell migration in vivo: a highly resolved in vivo magnetic resonance imaging investigation of experimental stroke in rat. Proc. Natl. Acad. Sci. 99, 16267-16272.

Koenig, S.H., Brown, R.D.I., 1987. Relaxometry of tissue. In: Gupta, R.K. (Ed.), NMR spectroscopy of cells and organisms, vol. 2. CRC Press, Boca Raton, pp. 75-114.
Lewin, M., Clement, O., Belguise-Valladier, P., Tran, L., Cuenod, C.A., Siauve, N., Frija, G., 2001. Hepatocte targeting with Gd-EOB-DTPA. Potential application for gene therapy. Invest. Radiol. 36, 9-14.

Louie, A.Y., Hüber, M.M., Ahrens, E.T., Rothbächer, U., Moats, R., Jacobs, R.E., Fraser, S.E., Meade, T.J., 2000. In vivo visualization of gene expression using magnetic resonance imaging. Nat. Biotechnol. 18, $321-325$.

Merisko-Liversidge, E., Liversidge, G.G., Cooper, E.R., 2003. Nanosizing: a formulation approach for poorly-water-soluble compounds. Pharm. Sci. 18, 113-120.

Moats, R.A., Fraser, S.E., Meade, T.J., 1997. A smart magnetic resonance imaging agent that reports on specific enzymatic activity. Angew. Chem., Int. Ed. 36, 726-728.

Modo, M., Cash, D., Mellodew, K., Williams, S.C.R., Fraser, S.E., Meade, T.J., Price, J., Hodges, H., 2002. Tracking transplanted stem cell migration using bifunctional, contrast agent-enhanced, magnetic resonance imaging. NeuroImage 17, 803-811.

Modo, M., Mellodew, K., Cash, D., Fraser, S.E., Meade, T.J., Price, J., Williams, S.C.R., 2004. Mapping transplanted stem cell migration after a stroke: a serial, in vivo magnetic resonance imaging study. NeuroImage 21, 311-317.

Okabe, M., Ikawa, M., Kominami, K., Nakanishi, T., Nishimune, Y., 1997. Green mice as a source of ubiquitous green cells. FEBS Lett. 407, 313-319.

Stanisz, G.J., Henkelman, R.M., 2000. Gd-DTPA relaxivity depends on macromolecular content. Magn. Reson. Med. 44, 665-667.

Terreno, E., Geninatti Grich, S., Belfiore, S., Biancone, L., Cabella, C., Esposito, G., Manazza, A., Aime, S., 2005. Effect of the intracellular localization of a Gd-based imaging probe on the relaxation enhancement of water protons. Proc. Int. Soc. Magn. Reson. Med. 13, 2622.

Terreno, E., Geninatti Crich, S., Belfiore, S., Biancone, L., Cabella, C., Esposito, G., Manazza, A.D., Aime, S., 2006. Effect of the intracellular localization of a Gd-based imaging probe on the relaxation enhancement of water protons. Magn. Reson. Med. 55, 491-497.

Zenke, M. Hieronymus, T., 2006. Towards an understanding of the transcription factor network of dendritic cell development. Trends Immunol. 27, 140-145. 